\title{
3 A família com criança autista: apoio de enfermagem
}

\author{
【 Maria Assunção Almeida Nogueira' ${ }^{1}$ Susana Carolina Moreira Martins do Rio
}

\section{RESUMO}

O autismo não sendo uma doença, para muitos, é considerado um grave sofrimento mental. Para a Medicina continua a ser um enigma que afecta, profundamente, quem dele padece e os que o rodeiam: a família. Esta perturbação mental implica problemas sociais, de comportamento e de linguagem. A criança autista requer cuidados exigentes de quem de si cuida: na esmagadora maioria os pais. Estes ficam expostos a múltiplos desafios, no dia-a-dia, quer económicos, emocionais, culturais entre outros. $\mathrm{O}$ apoio é fundamental para ajudar a família a lidar com a criança autista.

Conscientes da pouca informação sobre esta perturbação, que tende a ser mais frequente, sentiu-se a necessidade de realizar um estudo nesta temática com o intuito de contribuir para uma maior sensibilização dos profissionais de saúde, nomeadamente dos enfermeiros. Julgamos que a reflexão e compreensão das implicações que o autismo traz ao seio familiar, que envolvem os cuidados a ter com a criança autista, pelo cuidador principal, possam contribuir de modo a actuar, na prática, de maneira a atenuar estas implicações e sofrimentos.

É fundamental ter competências para saber avaliar estas famílias de modo a que a intervenção vá no sentido de se dar apoio à família/cuidador, assim como apontar estratégias de forma a minimizar o impacto da perturbação autista na vida familiar. A Enfermagem tem um papel decisivo nestas intervenções.

\section{PALAVRAS-CHAVE: Autismo, família, vivências,} enfermagem e cuidados

\section{SUMMARY}

Autism is not a disease, for many it is considered a serious mental illness. For medicine remains a troubling enigma affecting, deeply, who suffers from it and those around the family. This mental disorder involves social problems, behavior and language. An autistic child who requires demanding to whom takes care of them. Parents are exposed to multiple challenges on a daily basis, whether economic, emotional, cultural and others. The support is fundamental to helping families cope with the autistic child.

Aware of the limited information about this disorder that tends to be more frequent, it's felt the need to conduct a study on this subject in order to contribute to greater awareness among health professionals, particularly nurses. We believe that reflection and understanding of the implications that autism brings to their families, involving the care of the autistic child, by the main caregiver, can contribute to work in practice, so as to mitigate those implications and suffering.

It is essential to have abilities to assess these families so that the intervention goes in order to support the family / caregiver, as well as to point strategies to minimize the impact of autistic disorder in family life. Nursing has a key role in these interventions.

\section{KEYWORDS: Autism, family, experiences,} care and nursing.

\section{VIVÊNCIA DA FAMÍLIA COM FILHO AUTISTA}

As pessoas com autismo apresentam comportamentos particulares. Hockenberry, Wilson e Inkelstein (2006), definem o autismo como "um distúrbio evolutivo complexo do funcionamento cerebral acompanhado de uma ampla e gravidade de défices intelectuais e de comportamento" (p.618).

São variadas as dificuldades, alterações e necessidades que podem ser sentidas pela família, que tem, no seu núcleo, crianças com autismo e estas conduzem a um conjunto de vivências, que irão afectar a família em geral, tanto positiva como negativamente.

A partir desta constatação, questionamo-nos: quais as implicações que o autismo traz à família? Esta questão serviu de orientação ao estudo que surgiu de uma pesquisa, em que os objectivos foram:

- Identificar o impacto da família aquando do diagnóstico de autismo;

\footnotetext{
${ }^{1}$ Enfermeira, Professora Coordenadora, Departamento de Enfermagem, Instituto Politécnico de Saúde do Norte - Cooperativa de Ensino Superior Politécnico e Universitário (IPSN-CESPU), assuncaonog@gmail.com

Submetido em 10-09-2010. Aceite em 20-02-2011.

Citação: Nogueira, M. A. A. \& Rio, S. C. M. M.. (2011). A família com criança autista: apoio de enfermagem. Revista Portuguesa de Enfermagem de Saúde Mental, 5, 16-21.
} 
- Identificar dificuldades de uma família com um membro diagnosticado por autismo;

- Identificar alterações sentidas a nível social e familiar;

- Identificar necessidades de uma família, em que um dos seus membros tenha sido diagnosticado com perturbações autistas;

Para concretizarmos estes objectivos, procedemos à elaboração de um estudo exploratório descritivo, com uma abordagem qualitativa, mais concretamente uma história de vida.

A história de vida ou método autobiográfico leva os indivíduos a relatarem as suas "pequenas vivências" com a presença e assistência do investigador.

Neste estudo, recorreu-se a uma mulher, com 48 anos, mãe de uma criança, com 15 anos, a quem foi diagnosticada perturbações autistas. A intenção, da recolha de informação, era a de que esta mulher relatasse as suas vivências, isto é, pretendíamos explorar as dificuldades sentidas e, em geral, os embaraços que encontrou na comunidade/sociedade ao ter uma criança com distúrbio autista. Estávamos interessados em fazer levantamento das inúmeras expressões da vida desta mulher. Para isso, recorreu-se a entrevistas semi estruturadas, realizadas em dois momentos distintos, e posteriormente valendo-nos da técnica de análise de conteúdo, baseada nos discursos da entrevistada, apoiandonos em vários autores.

A principal finalidade da apresentação dos dados é exibir, de forma sistemática, as informações que obtemos. No quadro que se segue (denominado sistema de categorias e subcategorias) poderemos verificar vários aspectos, que esta perturbação trouxe à sua vida/família.

Quadro 1 - Vivência da família com criança autista (sistema de categorias e subcategorias)

\begin{tabular}{|c|c|}
\hline Categorias & Subcategorias \\
\hline Impacto da doença na família & $\begin{array}{l}\text { Revolta } \\
\text { Ansiedade / Preocupação } \\
\text { Aceitação }\end{array}$ \\
\hline Dificuldades experimentados pela família & $\begin{array}{l}\text { Gravidez } \\
\text { Informações sobre a doença } \\
\text { Desenvolvimento infantil } \\
\text { Educação } \\
\text { Escolaridade } \\
\text { Económicas }\end{array}$ \\
\hline Alterações a nível quotidiano & $\begin{array}{l}\text { Saúde } \\
\text { Relações familiares (entre irmãos, pais-filho e conjugal) } \\
\text { Relações sociais }\end{array}$ \\
\hline Verbalização de necessidades & $\begin{array}{l}\text { Apoio governamental } \\
\text { Apoio de profissionais de saúde e educação }\end{array}$ \\
\hline Estratégias adoptadas pela família & $\begin{array}{l}\text { Criação de um blog } \\
\text { Utilização dos meios de comunicação } \\
\text { Procura de diferentes profissionais de saúde }\end{array}$ \\
\hline Atitude dos profissionais de Saúde & $\begin{array}{l}\text { Negligência } \\
\text { Desvalorização de queixas }\end{array}$ \\
\hline
\end{tabular}

\section{IMPACTO DO DIAGNÓSTICO DO AUTISMO NA FAMÍLIA}

O impacto do diagnóstico de uma doença crónica, como é o caso do autismo, será a primeira dificuldade com que se confronta a família. Após terem comunicado, que o filho sofria desta perturbação à família, mais concretamente à mãe, fica em estado de "choque", dizendo: "Não é a mim que isto está a acontecer". Esta fase de negação caracteriza-se por uma defesa temporária, que mais tarde é substituída pela aceitação, ainda que parcial (Paúl \& Fonseca, 2001). Com este diagnóstico, a família tem que "viver" com uma doença que não tem cura.

Ao nível de aceitação do diagnóstico e da própria perturbação, a família pareceu-nos, estar adaptada, apesar de ter referido que foi inicialmente um processo complicado: "Eu aceito, seja ele autista, tenha um atraso, não tenha! Tenha ele o que tiver! Ele é meu filho! Eu aceito-o tal e qual como ele é!" (A mãe).

De acordo com Siegel (2008), após o diagnóstico de autismo, "para muitas famílias, a aceitação da perturbação da criança é um processo gradual, nunca concluído" (p.165). No entanto, o discurso, que obtivemos da entrevistada, contraria esta situação, admitindo que aceita a doença do filho.

Apesar do diagnóstico já não ser uma preocupação, a mãe admite que "agora não estou aflita com o diagnóstico". No entanto, ao longo da nossa conversa, foram perceptíveis diversas preocupações e ansiedades: "A minha maior angústia e preocupação é...quando morrermos... como quem é que ele vai ficar? Com que condições? Até lá, enquanto formos vivos, o que é que podemos fazer por ele? O que é que conseguimos obrigar o Estado a fazer, através da escola?".

Denota-se, assim, através destas afirmações, que as preocupações da família estão na sua maioria relacionadas com o que poderão fazer, as entidades públicas e/ou as privadas, para defender os direitos do filho e dar continuidade aos cuidados. Segundo Telmo (2005), a maioria dos pais desejam morrer depois dos filhos, pois não os querem deixar sozinhos. Este sentimento aumenta ainda mais o sentimento de culpa e impotência.

Poderemos verificar-se, com a análise dos dados obtidos, que vários sentimentos estão presentes e são apresentados sob a forma de revolta. Esta, na sua maioria, está relacionada com a forma como foram tratados quando procuraram ajuda, pela forma como tratam a doença, a criança autista e os próprios pais. A revolta é sentida ao constatarem a não existência de apoios e verificarem que a sociedade não se preocupa, ficando apática perante as dificuldades destas famílias, além de sentirem que não há relevância para esta perturbação mesmo ao nível de cuidados de saúde. Segundo Pereira (2005), o sentimento de revolta é um dos muitos que se verificam nestas famílias, entre os quais se destacam a desilusão, a raiva, a angústia, o protesto, a negação e a depressão. 
A existência destes sentimentos de revolta e ansiedade estão relacionados não só com a doença em si, mas também, como já se constatou, com dificuldades que foram surgindo no seio familiar. Segundo Pereira (2005), a família tem de se adaptar a uma nova carência. No ciclo de vida normal de qualquer família, terá de se adaptar às dificuldades e incapacidades de um membro com autismo. Como esta perturbação não tem cura, ainda se acentuam mais os sentimentos de ansiedade decorrentes das vivências diárias.

\section{DIFICULDADES EXPERIMENTADAS PELA FAMÍLIA}

Este filho foi muito desejado pelos pais e, ficando o casal muito feliz com a notícia da gravidez : "Foi uma gravidez desejada (...) havia muita vontade de termos um filho logo no início da nossa relação". No entanto, desde cedo, na gravidez, existiram vários problemas, incluindo a possibilidade de nado-morto: "Um rasgão na placenta...E comecei a perder sangue, fiz uma ruptura de placenta alta" e "vejo-a a ir lá fora e a comentar com a médica de serviço e com o pessoal "liguem já para o bloco, dado que temos uma cesariana de emergência, porque ela está com uma hemorragia interna. E os batimentos cardíacos do bebé estão a baixar e não sobem, estamos a perder o bebé!" (A mãe). Apesar destas dificuldades, a felicidade de ter, finalmente, um filho, tão desejado, não se desvaneceu. No entanto, os problemas que ocorreram durante o nascimento do bebé são também uma das causas de revolta da mãe, passível de se verificar na seguinte afirmação: "Isso nunca, nunca perdoei ao pessoal de serviço".

A falta de informação sobre a doença, junto dos profissionais de saúde, foi outra dificuldade manifestada. Esta família optou por procurar informação de imediato para ajudar o filho: "Quando eu comecei à procura de informação... sobre o autismo...A gente não conseguiu nada em português... Havia um site da APPDA (Associação Portuguesa para as Perturbações do Desenvolvimento e Autismo)! Acho que do Norte...tinha muito pouca informação, limitava-se apenas a dizer onde é que estava...e nada mais... E que estavam ali...Se a gente precisasse para ir lá ter com ele" (A mãe).

Face ao diagnóstico, "os pais sentem a necessidade de agir de imediato, fazer algo, e obter respostas o mais rapidamente possível" (Siegel, 2008, p.164).

A educação foi também uma preocupação da mãe. Educaruma criança com autismo torna-se, muitas vezes, uma frustração para os pais. No caso desta família, a criança não apresentava comportamentos, que demonstrassem falta de disciplina: " $E u$ não o vejo gozar, nunca, com ninguém, eu não o vejo maltratar ninguém, tirar satisfação do mal de alguém. Eu nunca vi o meu filho ter esse tipo de atitudes" (A mãe). O relato da entrevistada é contraditório ao encontrado na bibliografia. Segundo Siegel (2008), "há uma dinâmica básica que é estabelecida muito precocemente em algumas famílias, que se centra no medo de que a criança com autismo sinta qualquer forma de disciplina (...) Em algumas famílias, a criança com autismo, na realidade, governa o sítio. Faz o que the apetece, aos pais e aos irmãos, e destrói todo o tipo de artigos domésticos, no decurso do seu "jogo" habitual. Este tipo de dinâmica não é positivo para o crescimento e desenvolvimento da criança" (p.183). Esta dificuldade, sentida por algumas famílias, em crianças com perturbações do desenvolvimento, acaba por não estar presente nesta família.

Segundo Ozonoff et al. (2003), as crianças com autismo começam a apresentar problemas de desenvolvimento, nos primeiros dois anos de vida, como aconteceu nesta família, exigindo, segundo Pereira (2005), a família se adapta a esta nova realidade, além das exigências normais presentes no ciclo familiar. Terem que se adaptar a uma nova situação, a que não estavam habituados, constituiu, outra dificuldade experimentada por esta família.

Neste caso, foram várias as dificuldades que encontraram, desde uma escola para o filho, visto que, ninguém o aceitava, justificando que não tinham pessoal especializado para lidar com crianças nestas situações. Não obstante, e ultrapassadas as dificuldades iniciais, os pais conseguiram encontrar uma escola com técnicas especializadas e meios próprios para poderem trabalhar com estas crianças.

"Apesar de algumas das dificuldades experimentadas pelas pessoas com autismo serem comuns a outras formas de deficiência, há dificuldades específicas inerentes ao autismo que requerem compreensão e técnicas educativas especializadas que não são geralmente disponíveis nos ambientes educativos genéricos" (Telmo, 2005, p.114). Na verdade, e embora inicialmente, esta família fora confrontada com diversas dificuldades a nível da escolaridade do filho. Porém essas dificuldades começaram a ser ultrapassadas, ao encontrarem uma escola preparada para o ensino de crianças com perturbações do desenvolvimento.

Uma das dificuldades, mais exacerbada ao longo da entrevista, prendeu-se com questões económicas: "Eu tenho um rendimento baixo, tenho muitas dificuldades" (A mãe). Estas dificuldades acabam por influenciar todos os outros aspectos relacionados com a doença. $O$ facto de não terem recursos financeiros suficientes impedem os pais de manterem o filho em consultas mais especializadas e proporcionar-Ihe a qualidade de vida de que gostavam.

Uma criança autista requer inúmeros serviços de saúde: médicos, suplementos, terapia da fala, terapia física e ocupacional etc. Muitos são os gastos que nem todos os pais podem suportar, com a finalidade de melhorar as competências comunicacionais, comportamentais e os padrões sociais dos filhos.

Todas estas dificuldades acabaram por alterar a forma como viviam. 


\section{ALTERAÇÕES NO QUOTIDIANO FAMILIAR}

Foi evidente que ocorreram significativas alterações no quotidiano desta família.

Foi possível verificar que a saúde e o bem-estar dos pais foram alterados. Além de terem desmazelado a sua própria saúde, com as perturbações do filho, os pais começaram a desenvolver problemas psiquiátricos. Pareceu-nos que a prioridade era o bem-estar do filho, descurando a sua própria saúde.

Segundo a mãe, esta criança teve alguns problemas de saúde, que não foram detectados, precocemente, devido às manifestações do autismo e à dificuldade que existe em examinar estas crianças. Para Telmo (2005), as dificuldades para examinar a criança existem, mas com criatividade podem-se ultrapassar essas dificuldades. Acrescenta também que só se devem realizar os exames e consultas necessárias, sem exagero e sem cair na omissão. Em relação à família, considera-se necessário um bom acompanhamento psicológico.

A nível das relações familiares, e como referiu a mãe, "isto acaba por ter influências a nível emocional, familiar". Em termos da relação pais-filhos e entre os irmãos, denota-se que existe grande cumplicidade e carinho entre eles: "Também não o faz com mais ninguém, eu lá tinha coragem de sair e deixar o meu filho em casa? É impensável" e "Sei...que o irmão costumava tocar guitarra, às vezes, eles brincavam, cantavam, dançavam... Foi a única pessoa com quem o vi a dançar! Foi com o irmão... Lá no quarto, entre eles era uma animação...".

Todavia a relação conjugal, foi muito afectada, culminando com a separação: "Eu e o pai estivemos separados em consequência de um acumular de situações, que se vinham a arrastar... e para os quais já não tínhamos solução...porque chega a um ponto que já não temos...durante muito tempo..." Este tipo de discurso vem corroborar a opinião de Siegel (2008), que refere que embora sejam valores difíceis de precisar, cerca de metade dos pais, com crianças autistas, acabam por se separar, acontecimento que também ocorreu nesta família. Há um elevado número de divórcios nas famílias com filhos autistas, uma vez que as relações do casal passam por duras provas. No entanto, na bibliografia consultada, a este respeito, refere-se que, a maioria das separações ocorre antes de o filho ser diagnosticado, enquanto, neste caso, a separação ocorreu depois do diagnóstico e devido aos problemas que esta perturbação acarretou na conjugalidade.

Por último, a nível das relações sociais, verificou-se que a família deixou de ter o mesmo envolvimento social, utilizando a internet para estabelecer contacto com pessoas que não pertencessem ao seu agregado familiar. Pode também verificar-se que a família se sentiu afastada pelos amigos e pela família. Afastamento esse que culpabilizam pela falta de conhecimento que as pessoas têm sobre este tipo de perturbações e pelo medo de se confrontarem com os filhos. Segundo Siegel (2008), neste momento, supõe-se que as pessoas já saibam o que é "politicamente correcto", devendo demonstrar uma atitude de aceitação em relação a pessoas com necessidades especiais. No entanto, muitas vezes tal não acontece sendo os pais ainda criticados por serem maus pais, podendo, a criança ser evitada ou receber olhares de desprezo por ter aparência normal, mas ser "mal comportada" ou ter comportamentos desadequados.

\section{VERBALIZAÇÃO DAS NECESSIDADES}

Ao longo da entrevista, verificámos que uma família com um filho autista necessita de vários apoios. Segundo Telmo (2005), sendo o autismo uma doença crónica do desenvolvimento, a família e o autista necessitam de uma protecção diferente com vários níveis de apoio. Essas necessidades foram verbalizadas durante a entrevista, quer ao nível de apoios governamentais, quer ao nível de apoio dos profissionais de saúde e de educação.

A nível de apoio governamental, a entrevistada confessou considerando "o Estado não dar grandes apoios, embora tenha obrigações para com todos os membros da nossa sociedade". Segundo Telmo (2005), estas famílias desempenham um papel de extrema relevância quanto à educação e inclusão social destas crianças, uma vez que as autoridades públicas deveriam definir medidas adequadas às necessidades das famílias, facultando-Ihes o apoio necessário.

Ao nível de apoio dos profissionais de saúde e da educação, o mesmo se passou, existindo uma maior ênfase em relação à Enfermagem. Nesta área sanitária, nunca houve um envolvimento activo, no que diz respeito ao autismo e às consultas: "Se podermos associar uma coisa a outra, da mesma forma que, se houver, mesmo na escola, uma maior interacção entre a família e a escola, se calhar os resultados aparecem. Pode até ser a passo de caracol, mas acabarão por aparecer. Porque há um interesse, há um empenho" e "O elemento Enfermeiro, o elemento Enfermagem nunca estiveram presentes. Nunca! Nem no centro de saúde, nem na consulta externa, nem na consulta de autismo. Em lado nenhum eu vi um Enfermeiro. Vi um pedopsiquiatra, vi pediatras, vi neurologistas, vi técnicos de educação especial, mas não vi outros profissionais e saúde" (A mãe).

Embora o enfermeiro tenha sido um profissional que até ao momento não estivesse relacionado directamente com a família, a entrevistada considera que a sua presença e actuação, no que concerne o autismo, poderá ser relevante: "O enfermeiro é a pessoa que está mais próxima da acção, da atitude, dos cuidados primários. Mais próximo da família poderá ser uma ponte." 


\section{ESTRATÉGIAS ADOPTADAS PELA FAMÍLIA}

De forma a conseguir lidar com as dificuldades e alterações com que se depararam, os membros da família adoptam algumas estratégias:

Uma das primeiras adoptadas pela família foi a criação de um blog, de forma a colmatar a falta de informação, ajudar famílias que estivessem na mesma situação e pela necessidade de encontrar alguém que os ajudasse a entender esta perturbação e ajudasse o filho.

Segundo Giddens (2008, p.475.), "A internet (...), esbatendo fronteiras entre o global e o local, apresenta novos canais para comunicação e interacção". Foi este "quebrar" de barreiras, que esta família procurou, na tentativa de encontrar soluções para o problema, com que se deparou na saúde do filho;

Outra das estratégias que utilizou foi a utilização dos meios de comunicação Social, que entraram em contacto com eles, para transmitirem a sua experiência e darem ênfase às necessidades das famílias que convivem diariamente com um doente de autismo. Esta forma foi a encontrada para que conseguissem dar "voz" às pessoas que não tinham oportunidade de o fazer e passavam pelas mesmas dificuldades. Embora a mãe, como referiu ao longo da entrevista, fosse contra os meios de comunicação, acabou por comparecer num programa televisivo, evocando alguma atenção para estas perturbações e para as necessidades que estas famílias sentem;

Por último, a família procurou diferentes profissionais de saúde, na tentativa de encontrar soluções e formas de ajudar o seu filho a ultrapassar ou a atenuar todas as manifestações do autismo. Segundo Siegel (2008), esta atitude, de procura de diferentes profissionais, é uma estratégia que vários pais adoptam, uns porque não querem aceitar o diagnóstico, outros porque reconhecem que o diagnóstico de autismo é difícil. Naturalmente, querem certificar-se que não existiram equívocos ou então querem descobrir se alguém Ihes apresenta diferentes formas de tratamento.

\section{ATITUDE DOS PROFISSIONAIS DE SAÚDE}

Sendo os enfermeiros profissionais de saúde, considerouse pertinente analisar a atitude de todos estes profissionais, perante a família e a criança com autismo. Nesta área, deparamo-nos com duas subcategorias: a negligência e a desvalorização de queixas.

Uma das atitudes dos profissionais de saúde mais salientada foi a negligência. A entrevistada julga que, e tendo conhecimento que não se sabe a causa do autismo, os problemas durante o parto possam ter algum relacionamento com o surgimento desta perturbação. Além disso, alguns comportamentos, que os profissionais de saúde tiveram com o seu filho, foram considerados como negligência: "Comecei eu a fazer-Ihe o penso porque ele tinha feito uma infecção. Eu só tinha consulta ao $15^{\circ}$ dia após a intervenção. Antes não o viam" e "Ainda estou á espera...que o chamem...para a consulta...E já estou aqui em Coimbra" (A mãe).

Outra atitude que os profissionais de saúde tiveram com a entrevistada, conforme a própria afirmou, foi a desvalorização de queixas: "Entretanto, o pediatra disse sempre que não, que não era nada. Ele não era nada autista, ele precisava era de ir para um infantário" e "Eu tentei chamar a atenção deste aspecto que considero importante, junto de médicos e terapeutas e nunca ninguém levou a sério, aquilo que eu dizia" (A mãe).

Esta mãe considerou que os profissionais de saúde nunca valorizaram as queixas, assim como sempre encararam as suas opiniões e indicações irrelevantes para os tratamentos. Nos últimos anos, tem-se vindo a verificar a necessidade de incluir os pais como parceiros no tratamento destas crianças. (Ozonoff et al.2003). Esta afirmação vai ao encontro do que a entrevistada procura, mas que não se verifica na realidade.

\section{CONCLUSÃO}

Estas notas finais não devem ser interpretadas como uma "conclusão", como um fim, mas devem ser encaradas como um impulso para a realização de mais trabalhos no âmbito desta temática.

No decorrer do trabalho foi notório que são diversas as implicações que um filho autista acarreta à família, salientando-se as dificuldades económicas, a falta de apoios e a negligência da qual esta família acredita ter sido vítima.

Considerou-se, segundo a opinião desta família/mãe, que deverá ser talvez necessário um maior interesse e empenho por parte dos profissionais de saúde, para com as necessidades vivenciadas por estas famílias. O papel do enfermeiro poderá ser relevante para estas famílias, podendo servir como ponte para uma comunicação categórica entre a equipa médica e a família que nunca deverá ser renegada. Além disso, o enfermeiro deveria assumir um papel mais relevante nestas famílias, exigindo um lugar de destaque na comunicação e na interacção com a família e a própria criança.

Julgamos que este estudo poderá contribuir para uma melhor compreensão do sofrimento das famílias com criança autista. A Enfermagem poderá intervir de forma mais eficaz, correspondendo às necessidades das famílias com crianças especiais. 


\section{REFERÊNCIAS BIBLIOGRÁFICAS}

Hockenberry, M. J.; Wilson, D.;. Inkelstein, M. (2006) Fundamentos de Enfermagem Pediátrica Wong ( $7^{\mathrm{a} e d}$.). Rio de Janeiro. Elsevier Editora.

Fortin, M. F. (2003) O processo de investigação. Da concepção à realização.( $3^{\mathrm{a}}$ ed.). Loures. Lusociência.

Giddens, A. (2008) Sociologia (6 ${ }^{\mathrm{a}}$ ed.). Lisboa. Fundação Calouste Gulbenkian.

Ozonoff, S.; Rogers, J.; Hendren, R. (2003) Perturbações do Espectro do Autismo - Perspectivas da Investigação Actual (1 ${ }^{\text {a }}$ ed.). Lisboa. Climepsi Editores.

Paúl, C.; Fonseca, M. (2001). Psicossociologia da Saúde. Manuais Universitários. Lisboa: Climepsi.
Pereira, M. C. (2006) Autismo - A família e a escola face ao Autismo ( $2^{\mathrm{a}}$ ed.). Vila Nova de Gaia. Gailivro.

Pereira, M. C. (2006) Autismo - Uma perturbação do desenvolvimento ( $2^{\mathrm{a}}$ ed.). Vila Nova de Gaia. Gailivro.

Siegel, B. (2008) O Mundo da Criança com Autismo: Compreender e tratar perturbações do espectro do autismo ( $2^{\mathrm{a} e d}$.). Porto. Porto Editora.

Telmo, I. C. (2005) Manual de Educação de Adultos com Autismo. Lisboa. APPDA - Lisboa, Associação Portuguesa para as Perturbações do Desenvolvimento e Autista.

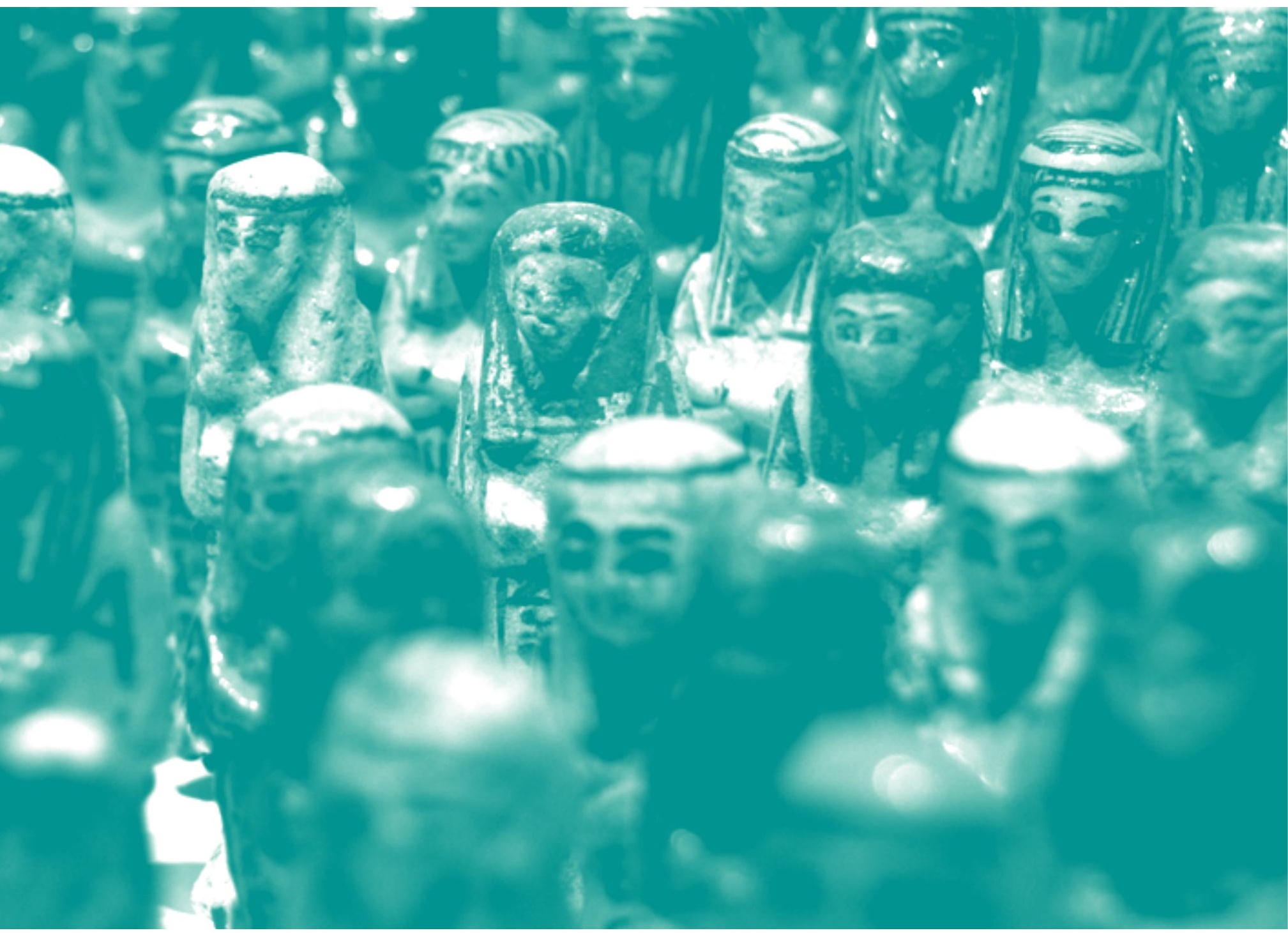

